\title{
Current Research Evaluation Topics in Social Sciences*
}

\author{
Zehra Taşkın \\ Adam Mickiewicz University, Scholarly Communication Research Group, Poznań, Poland \\ zehrayanar@gmail.com \\ https://orcid.org/0000-0001-7102-493X
}

\begin{abstract}
The social sciences, as a collection of scholarly fields, have quite different characteristics compared to STEM (science, technology, engineering, and medicine) fields. Still, researchers in the social sciences have been evaluated similarly to researchers in STEM for many years. However, many studies have been published regarding the need to evaluate social sciences differently. This chapter examines research evaluation studies published in social sciences and presents the advantages and disadvantages of current research evaluation topics including altmetrics, content-based citation analysis, peer-review, and scientific visualization.
\end{abstract}

Keywords: Research evaluation in social sciences, altmetrics, content-based citation analysis, social network analysis, scientific visualization

\section{Introduction}

In the past, science was a word used to describe the natural sciences. Some scientists even defined the social sciences as quasi-science (Huang \& Chang, 2008, p. 1819). While investigating the information-seeking behaviours of scientists, the first groups to be studied were natural scientists, followed by engineers, and only later on information-seeking behaviours of social scientists began to be studied (Line, 1971, p. 412).

A similar development emerges for research evaluations. In the beginning, evaluations were carried out to assess the scientific outputs produced by natural scientists (Marjanovic et al., 2009, p. 9). The first citation index, the Science Citation Index, was designed for STEM fields. Several years later Garfield mentioned the importance of creating an index for social sciences, despite all the obstacles social sciences have (Garfield, 1964, p. 61). He also indicated that citation indexes were the tool to close the gap between pure and applied sciences (Garfield, 1963). Besides, Line (1971, p. 420) found out that more than half of the social scientists requested a citation index for their field, but it was hard to know whether they would actually use it once provided. After the foundation of the Social Sciences Citation Index in 1973, social scientists have used it especially for evaluating research outputs.

\footnotetext{
* This paper is the author copy of a book chapter written for "Handbook on Research Assessment in the Social Sciences".

Taşkın, Z. (2021). Current research evaluation topics in social sciences. In T.C.E. Engels \& E. Kulczycki (Eds.), Handbook on Research Assessment in the Social Sciences. Edward Elgar Publishing. (ISBN: 9781800372542)
} 
Over the years, the necessity to consider disciplinary differences in research evaluation systems has emerged and many studies have been carried out on the need to evaluate social sciences and humanities differently (e.g. Huang \& Chang, 2008; Waltman, 2016; Wilsdon et al., 2015). Several of these studies concluded that the types of research outputs, citation patterns and main features of cited documents, perspectives on interdisciplinarity, production languages, national and international publication patterns, production speed and collaboration habits in the social sciences have field-specific characteristics. From this point of view, the research policies to be developed for social sciences should be specific to the field. Today, many initiatives and movements have been launched to show the emerging need for different assessment methods for social sciences (e.g. European Network for Research Evaluation in the Social Sciences (https://enressh.eu/); Hicks et al., 2015; Wilsdon et al., 2015).

The main aim of this chapter is to reveal the current topics of research evaluation studies in social sciences and present the most used approaches of social science research evaluation systems.

\section{Methodology}

To achieve the aim of the study, I evaluated all papers published on research evaluations in social science journals and indexed in Web of Science. I downloaded the metadata of 7254 papers from the Web of Science core collection and created the first dataset (see Table 1 for the method of selection of papers). Then, studies that have social sciences as a term in the title, abstract and/or keyword fields were selected to create the second dataset. The main limitation of this selection is the possibility of missing the research evaluation studies conducted on specific subject fields of social sciences such as history or law and which do not have social science in the title or abstract. For this reason, it should be noted that the analyses based on the second dataset provide information about research evaluation studies of social sciences in general.

After creating the first two datasets, current topics were determined as altmetrics, citation context, peer-review and scientific visualization and four more datasets were created using the Web of Science Social Sciences Citation Index (SSCI) which covers journals from social sciences. However, the limitation of this choice is the research evaluation articles on STEM fields which were published by social science journals. The keywords used to gather article metadata for each dataset are shown in Table 1.

Another limitation relates to the data source. It is a well-known fact that books and monographs are as important as journal articles in social sciences (Kulczycki \& Korytkowski, 2020), and social scientists often produce local language papers (Kulczycki et al., 2020). However, choosing Web of Science as a data source limits the results to, mainly, journal articles and English language content. However, considering the research articles are the first venues where the current problems of science are discussed, it is possible to say that article data allows us to draw a general framework to understand emerging research topics. The main structures of the datasets, their contents and coverages are shown in Table 1. 
Table 1. The main structures of datasets, their contents and coverages

\begin{tabular}{|c|c|c|c|}
\hline Dataset & $\begin{array}{l}\text { Nof } \\
\text { pub. }\end{array}$ & Search query & $\begin{array}{r}\text { Years } \\
\text { covered }\end{array}$ \\
\hline 1. Research evaluation & 7254 & $\begin{array}{l}\text { TS=("research evaluation*" OR "research assessment*" OR } \\
\text { "evaluating research*" OR "assessing research*" OR "research* } \\
\text { impact*" OR "research metrics" OR "research excellence" OR } \\
\text { "bibliometric evaluation*" OR "bibliometric assessment*" OR } \\
\text { "scientometric evaluation*" OR "scientometric assessment*") }\end{array}$ & $1926-2020$ \\
\hline 2. ... social sciences & 511 & $\ldots A N D T S=("$ social science $* ")$ & $1993-2020$ \\
\hline 3. Altmetrics & 509 & $\begin{array}{l}\text { TS=(altmetrics } O R \text { "alternative metric*" OR "social media research } \\
\text { metric } * ")\end{array}$ & $2005-2020$ \\
\hline 4. Citation context & 350 & $\begin{array}{l}\text { TS }=(" \text { citation motivation } * \text { "OR "citation behavior*" OR "citation } \\
\text { behaviour*" OR "content based citation" OR "content-based } \\
\text { citation" OR "citation context*" OR "citer motivation*" OR } \\
\text { (sentiment AND citation) OR "citation categorization" OR "citation } \\
\text { categorisation" OR "positive citation } * \text { "OR "negative citation*" OR } \\
\text { "perfunctory citation*" OR "citation classification" OR "citation } \\
\text { semantic") }\end{array}$ & $1965-2020$ \\
\hline 5. Peer-review & 4338 & $T S=(" p e e r-$ review" OR "peer review") & $1971-2020$ \\
\hline 6. Visualization & 8076 & $\begin{array}{l}\text { TS=("social network analys*s" OR "co authorship" OR "co- } \\
\text { authorship" OR "coauthorship" OR "co-citation" OR cocitation OR } \\
\text { "scientometric visuali*ation" OR "bibliographic coupling" OR } \\
\text { ("visuali*ation" AND "research output*")) }\end{array}$ & $1963-2020$ \\
\hline
\end{tabular}

Before analysing the datasets, I cleaned and standardized the data. In the standardization process, the singularization of plural words (e.g. index, indexes) and unification for different variations of the keywords (e.g. organization, organisation) and abbreviations (e.g. SSCI, Social Sciences Citation Index) were done.

I used VOSviewer to create keyword co-occurrence and co-word networks of title and abstract terms. Since the size of each dataset differs, detailed explanations about creating each network are presented in the findings section.

\section{Findings}

\section{Research Evaluation in Sciences and Social Sciences}

Research evaluation is one of the most important subjects in all scientific fields. Decision-makers and managers sometimes prefer to determine the scientific levels of researchers using certain numbers, e.g. grant income, publications, citations to these publications and patents awarded. In turn, such numbers may also influence funding decisions. Although such numbers are sometimes meaningful, it is quite problematic to use such numbers in the process of research evaluations in the social sciences. William Bruce Cameron (1963, p. 13) indicated that it would be nice to enumerate all the data on sociology to draw perfectly designed charts, however, "not everything that can be counted counts, and not everything that counts can be counted". Cameron's approach is valid for the whole of the social sciences. We must consider the countables and uncountables in research evaluation tasks in the social sciences. 
In the research evaluation literature, studies aim to reveal the importance of research evaluation, the methods and the tools for it. For all research evaluation literature, the first study that appeared in WoS is Evaluating Research Ideas, which was published in 1926 (Clements, 1926). In the article, Clements stated that industrial production should be based on science, and he specified that scientific research projects should reduce production or usage costs, increase the sales of products, create new business areas or produce technical information. Hence research evaluation was product-oriented at first. However, over the years, the topics of studies written on research evaluation have diversified and studies that look at research evaluation from different angles have been published. One of the most important development is the realization that disciplinary differences should be considered in research evaluations. Figure $1^{1}$ shows both the thematic distribution of publications written on research evaluation in general and the structure of social sciences research selected among these publications.

From the keyword co-occurrence map of all research evaluation studies (See Figure 1-a) three subject clusters and a few related small subject clusters emerge. The most prominent keywords of research evaluation studies are presented in the red cluster that shows basic research evaluation topics such as metrics, indicators and measurement methods. The green cluster represents studies on the impact of research and related research policy development issues. The blue cluster indicates that research evaluation in the field of health and clinical research is an important subject of research evaluation studies. In recent studies, the most frequently used words are open science, co-production, societal impact, social media analysis, altmetrics and commercialization of academia.

Figure 1-b shows the keyword co-occurrence network of research evaluation studies in social sciences. According to the Figure, research impact is one of the prominent topics in social science research evaluation studies. Also, the topics of social science research evaluation studies cover a wide variety of subjects including book publishing, citation characteristics, quality indicators, gender inequality, bias, visibility and peer-review. Topics currently being studied are open science, social media, book publishing, multilingualism, citation classification and ethics. The diversity of subjects in social science research evaluation studies is worth noting.

\footnotetext{
${ }^{1}$ Full counting method was selected to create the maps. The top 500 keywords which are occurred at least 10 times in Dataset 1, and the top 200 keywords which are occurred at least 3 times in Dataset 2 were presented in the networks.
} 

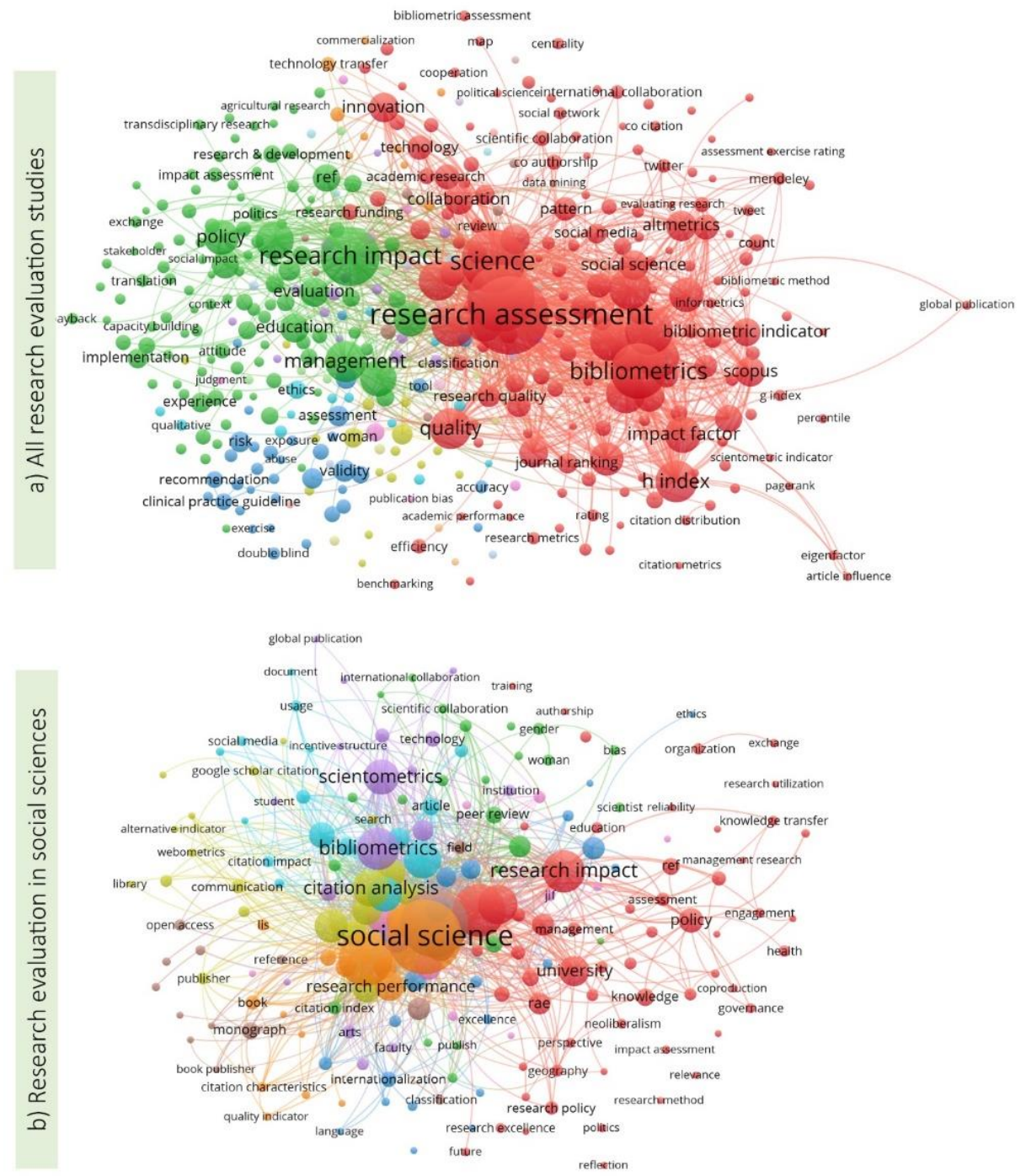

Figure 1. Co-occurrence network of research evaluation studies (a) and research evaluation studies mentioning the social sciences $(b)^{2}$

After understanding the emerging subjects of the field, four main directions were defined as the current topics of research evaluations in the social sciences: 1) Altmetrics, 2) Content-based citation analysis, 3) Peer-review and 4) Social network analysis.

\section{Current topics of research evaluation studies}

Understanding the new concepts in research evaluation studies and their application areas is important for research policy. Figure 2 shows the subject evolutions of each of the four main topics. In this section, basic definitions of each emerging research topic are given, and predictions are made considering the development of the topics over the years.

\footnotetext{
${ }^{2}$ For overlay visualization of keyword co-occurrence map, see Appendix 1.
} 

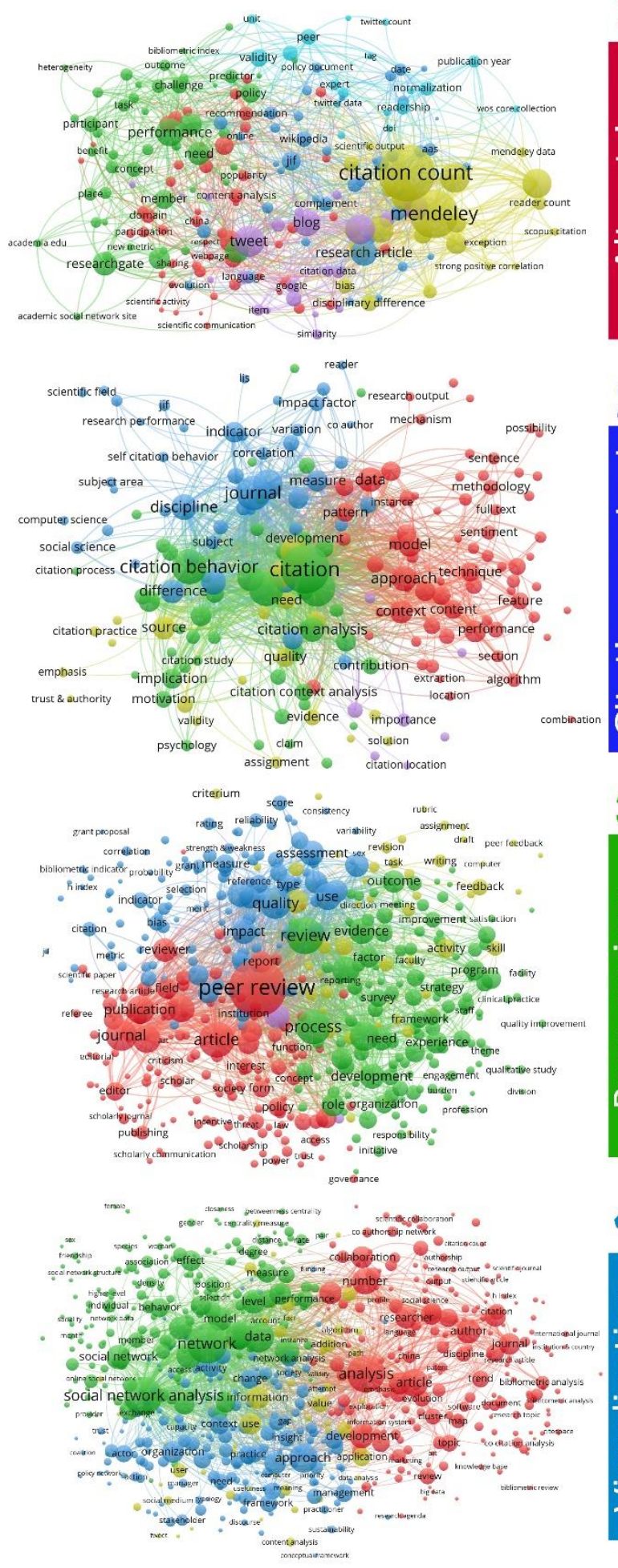
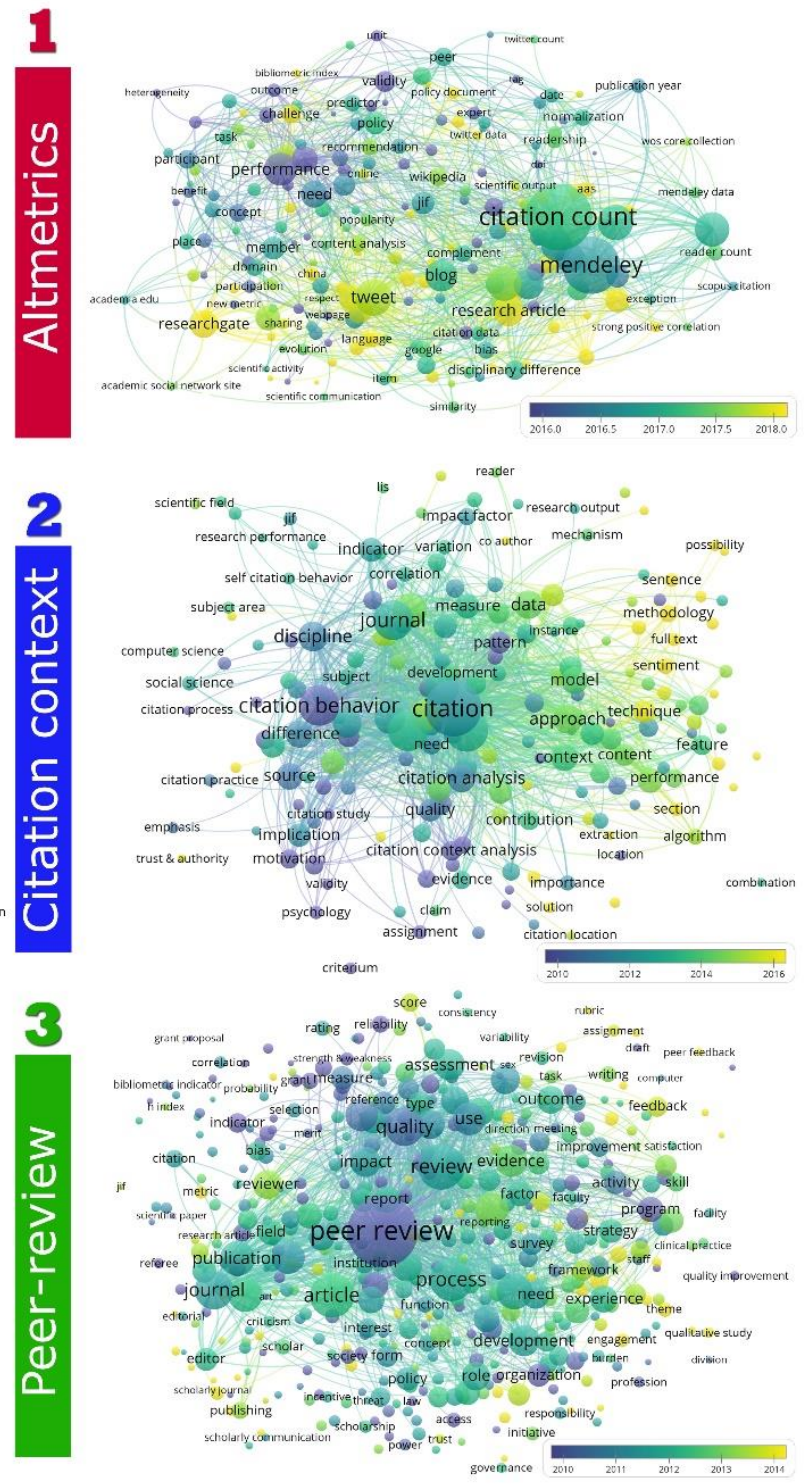

Figure 2. Co-word maps of research topics based on title and abstract terms (timeline map of each dataset is available at http://zehrataskin.com/handbookSS/4fields.jpg $)^{3}$

\footnotetext{
${ }^{3}$ While the thematic distribution of each subject category is given on the left side of the figure, the yearly trends are shown on the right.
} 
Using social media as a research evaluation tool: Altmetrics

Social media is defined as "forms of electronic communication (such as websites for social networking and microblogging) through which users create online communities to share information, ideas, personal messages, and other content (such as videos)" (Merriam-Webster, n.d.). Considering this definition, the history of social media dates back to 1971, when the first email was sent (Swatman, 2015). Since then, people have been using diverse social media platforms to communicate with their friends and families, share their ideas or enjoy life. Social media has become an important part of our lives. With the outbreak of social media platforms like Twitter, Facebook, YouTube etc., for researchers looking for "alternative" ways of research performance evaluations, a new concept emerged: Altmetrics. In 2010, Priem et al. (2010) published an Altmetrics Manifesto to propose an alternative way to traditional evaluation systems. Since then, studies on altmetrics have been conducted on various sub-topics.

Altmetrics, also known as alternative metrics, are web-based metrics using social media outlets like reference managers, research blogs and Twitter as sources of data (Shema et al., 2014, p. 1019). The keywords that have the highest centrality rates in the Altmetrics network are citation (0.22), social media (0.17), science $(0.11)$ and Mendeley $(0.10)$ while the most-frequent keywords were altmetrics (316 times), impact (135 times) and social media (125 times). According to Figure 2-1, which was created by using the title and abstract fields of altmetrics papers, six subject clusters emerge. These are \#1: Research evaluations (red), \#2: Social networks designed for academia (green), \#3: Comparisons of traditional and alternative metrics (blue), \#4: Evaluations by Scopus and Mendeley data (yellow), \#5: Social media platforms and metrics (pink) and \#6: Validity of altmetrics and impact measures (turquoise). The starting point of studies seems to be the search for the alternative impact measure for science. Priem et al. (2010) explained how the use of altmetrics might facilitate research evaluation in an era where the number of publications is impossible to read the peer-review system is considered old-fashioned, and citation counting, and journal indicators have proofed insufficient. Keywords such as open access and peer-review in the timeline network show that similar discussions are still ongoing in the altmetrics literature. Other current subjects in altmetrics are studies on academic networks such as ResearchGate and Academia.edu, the use of altmetrics in policy, the determination of the societal impact of research, the analysis of specific journals and critical analysis of altmetrics.

Criticisms are important studies because altmetrics were launched as an alternative to traditional metrics. However, most of the studies indicated that altmetrics alone cannot be used in research evaluations due to the problems it has. In 2003, some papers claimed that it was too early to use altmetrics for evaluation purposes on account of its drawbacks and data quality issues (Buschman \& Michalek, 2013; Cheung, 2013). Four years later, Williams (2017) suggested improving technical and theoretical issues of altmetrics to overcome the main problems including not being an alternative to traditional citation analyses, the possibility of data manipulations, lack of definitions, heterogeneity of the social media platforms and language bias. In one of the most recent publications, Thelwall (2020) listed the currently ongoing issues of altmetrics, i.e. selecting indicators not matching the goals, using sparse indicators, ignoring field differences and 
publication years, calculating arithmetic means, reporting Pearson correlations for skewed data, overinterpreting correlations, treating altmetrics as unbiased, using hybrid indicators, not reporting data collection date and methods, failing to conduct an effective literature review and using alternative indicators for formal evaluations.

On the other hand, researchers working in the field of informetrics stated that although the use of traditional metrics may be advantageous for STEM fields, altmetrics provide a more useful assessment tool, especially for social sciences and humanities (SSH) (Liu et al., 2020, p. 373). The main reason for this usefulness is the importance of societal impact in the SSH. The subjects that are related to the public must be delivered to its audiences, therefore, social media has an important role in the social sciences and measuring social impact can be achieved to some extent by alternative metrics. Similarly, Giménez-Toledo (2018, p. 9) indicated that data issues notwithstanding, altmetrics have an important role in research evaluations in the social sciences.

The current altmetrics studies in the literature cover combining natural language processing techniques and altmetrics. NISO Alternative Assessment Metrics Project (National Information Standards Organization, 2016) and using machine learning techniques to understand the contents of social media posts are promising for the future of altmetrics (Hassan et al., 2020).

\section{From citation motivations to content-based citation analyses}

With the establishment of the Institute for Scientific Information in 1956 and Science Citation Index in 1960 (Clarivate, 2018), policymakers responsible for research evaluations gained a tool with capabilities they had not had before. This tool presented the numbers of publications and citations, and this made the job of policymakers much easier. During this period, the question of why researchers cite others was discussed by the experts, and Garfield, the creator of citation indexes, listed researchers' motivations to cite as paying homage to pioneers, giving credit to related papers, explaining methods, providing background information, correcting or criticizing previous work, proof support, forecast future studies, validating data, identifying original theories, disclaiming negative claims etc. (Garfield, 1970, p. 85). Garfield (1973, p. 407) also indicated as a reply to the concerns of his colleagues about using citation data for research evaluation purposes that citation data is a measure of research activity and the use of citation data in evaluating individual performance can be valid only as a starting point. However, since then, citation data and derived metrics such as the h-index have been an essential part of research evaluation systems in many countries and at many institutions. Hence it is no surprise that plenty of articles have been published about why the use of citation frequencies in performance evaluations is insufficient (e.g. Bornmann \& Daniel, 2008; Chubin \& Moitra, 1975; Moravcsik \& Murugesan, 1975; Tahamtan et al., 2016).

Although I call the content-based citation analysis a "current research topic", according to the co-citation analysis, the average publication year of 324 cited references cited at least 5 times in Dataset 3 was 1995 (median: 2001) and the prominent papers in the subject were older studies. They were: Some results on the function and quality of citations by Moravcsik and Murugesan, What do citation counts measure? A review of studies on citing behavior by Bornmann and Daniel and Content analysis of references: Adjunct or alternative to citation counting? by Chubin and Moitra. 
Although understanding citation contents is not a new subject for information science, it has become easier to understand citation contents thanks to the continuing development of computational linguistics and machine learning techniques. Almost 50 years ago, Chubin and Moitra (1975, p. 424) stated that understanding the content of citations is important for research evaluations yet almost impossible in practice because it required reading whole texts. Content-based citation analyses are much easier today because the texts are read and analysed by machines, not people.

According to Figure 2-2, the main subjects of content-based citation analyses articles are \#1 automated citation content classification (red), \#2 citation behaviour (green), \#3 comparisons of traditional citation counting and content-based citation analyses (blue) and \#4 citation practices in research evaluations (yellow). The pink cluster including only seven keywords about automated content classifications could be considered as a part of the red cluster. The most used keywords that have the highest centrality rates were citation behaviour (frequency: 116, centrality: 0.24) and citation analysis (frequency: 83, centrality: 0.23). Besides, the emerging topics of the contentbased citation analysis studies were citation sentences, citation sections, citation sentiments and automatic classification of citations. Such studies analyse the semantic and syntactic structures of citation sentences and classify citation sentences automatically. I created one of the recent citation classification schemes including four main citation classes: citations in terms of meanings (positive, negative and neutral citations), purposes (literature, methods, data etc.), shapes (quotation marks, multiple citations etc.) and arrays (citation section, number of uses in the texts etc.) (Taşkıın \& Al, 2018).

It is possible to follow a wide variety of classification schemes in recent literature because many content-based citation analysis projects have been carried out, and many articles have been published in recent years. Also, various reviews were written to summarize the works for contentbased citation analyses (e.g. Ding et al., 2014; Iqbal et al., 2020) and a platform was designed to provide citation contents called scite.ai.

Content-based citation analyses using automated techniques will be the new research direction for citation analyses and I believe that "citation analysis 2.0" will become common. However, we should not forget an important reality: One of the reasons for the emergence of contentbased citation analysis is the dysfunctionality of traditional citation counting. Unfortunately, as new metrics are being created recently such as the scite index (https://scite.ai/journals), traditional counting may remain as the main problem of research evaluations. Careful steps must be taken to provide effectiveness for content-based citation analysis studies.

\section{The power of transparent and open-peer-review}

The common understanding of the way of evaluating science qualitatively is a well-designed peerreview system. The peer-review system is sometimes referred to as the "principal mechanism for quality control" (Bornmann, 2011, p. 199). The system based on the opinions of peers about articles, grant proposals or fellowships to decide whose work will be published or funded. The fundamental principle of peer-review is that experts assess the professional performance, creativity and/or quality of scientific works which match their qualifications (Lee et al., 2013, p. 2). 
There are two traditional types of peer-reviews: 1) single-blind, in which reviewers are aware of the names of authors but authors do not know the reviewers and 2) double-blind, in which the two actors of the process do not know each other (Tomkins et al., 2017, p. 12708). However, issues relating to prestige, nationality, language, affiliation and gender biases (Lee et al., 2013; Tomkins et al., 2017) emerge through the word bias as one of the most important keywords of the literature on peer-review. Therefore, I advocate changes to the traditional peer-review system. These changes have started to occur with the introduction of the concept of open and transparent peer-reviews and post-publication peer-review.

Figure 2-3 shows that four subject categories were determined for the dataset 4 as \#1 the actors, outputs and processes of scholarly communication (red), \#2 evaluation studies on the peerreview system (green), \#3 bibliometric indicators, questionable research practices and bias in peerreview (blue) and \#4 writing feedbacks for peer-review (yellow). The evolution of keywords provided as a link in Fig. 3's caption shows the subject evolution of peer-review. Over the last 10 years, various studies have focused on incentives for peer-review, the impact of open science, the power of open peer-review and post-publication peer-review.

Some of the current approaches that aim to enhance the traditional peer-review system can be defined as (Horbach \& Halffman, 2018; Kovanis et al., 2017; Triggle \& Triggle, 2007):

- Open and transparent peer-review: This is not limited to knowing the names of peerreviewers, it is also about openly available peer-review reports for everyone. Open and transparent peer-review may also include interaction between authors and peer-reviewers. In my modest opinion, the future of the peer-review system depends on openness and transparency.

- Crowdsourcing, immediate publication and post-publication peer-review: In this system, publications are accepted as "discussion papers" and a crowd of peer-reviewers are chosen considering their expertise in the scientific disciplines. They evaluate the papers in a public online forum. While one of the problems of traditional peer-review processes is the duration of peer-review, this new approach will make the process shorter and more transparent (Ausserhofer, 2017). This approach requires well-designed pre-print servers and online forums and is likely to shape scholarly communication in the future.

\section{Visualizing collaborations and convergences: Social network analyses}

All people, institutions or events are tied to one another by invisible bonds, just like a fishing net. These bonds provide important information about relationships and social realities (Scott, 1988, p. 109). The analysis of social networks consists of measurements on a variety of relations for one or more sets of actors and it includes mathematical and visual representations of the relations (Wasserman \& Faust, 1994, p. 67). In recent years, social network analysis has been used in the field of bibliometrics for various purposes such as conducting the thematic analysis of disciplines and understanding convergent areas, revealing citation networks, visualizing collaboration 
patterns, and determining core journals and prominent authors. All the aspects of these analyses are important subjects of research evaluations.

The first paper in dataset 5 was published in 1963, however, more interestingly, more than half of the 8076 papers in the dataset were published in the last five years. This recency shows that studies on social network analysis are popular recently. The main reasons for this popularity are that social network analysis can be applied to almost all scientific disciplines and that a wide variety of tools and software for social network analysis is available. Today, citation databases are used as data sources to perform social network analyses, and scholars in bibliometrics use a variety of open-source software (such as CiteSpace, VOSviewer, Pajek and Gephi) which are compatible to visualize citation data.

Figure 2-4 shows that the main topics in visualization studies relating to research evaluation are \#1 Using social network analysis for bibliometric visualizations (red), \#2 Social network analysis and practical implications (green), \#3 Social network analysis in management sciences (blue) and \#4 Social media analysis techniques (yellow). The most frequent keywords of the network are social network analysis (frequency (f): 2831, centrality (c): 0.05), social network (f: 979, c: 0.05) and science (f: 884, c: 0.04), while the keywords that have highest centrality rates are gender (f: 103, c: 0.10), management (f: 548, c: 0.08) and intellectual structure (f: 206, c: 0.08). In addition to these keywords, performance, Twitter and diffusion have 0.07 centrality rates in the network even though their frequencies are low. The topics and the diversity of keywords illustrate the wide applicability of social network analysis.

Many reviews nowadays present "A bibliometric overview of...”. Nowadays social network analysis is recommended even for structuring literature reviews and new tools such as Connected Papers (https://www.connectedpapers.com) help researchers in this process. However,

evaluating only publications cited by papers indexed in core indexes, or analysing only specific journals or document types will cause the existing Matthew effect in science to increase exponentially (Merton, 1968). A publication that has been cited at least once will continue to be cited in the future. For this reason, even though such systems advertise with slogans such as "do not miss important publications in your field", they may cause important sources to be overlooked. On the other hand, social network analysis can reveal emerging/trending subject areas, provide researchers at the beginning of their career with basic information about their fields, enable funders to analyse the return of projects funded, and most importantly, it can facilitate measuring social impact. Social network analysis and visualization will be used frequently in future studies and will continue to contribute greatly to the development of research evaluation studies.

\section{Discussion and Conclusion}

This chapter presents a bibliometric overview of the methods and approaches used in recent studies on research evaluation in the social sciences. Just because research evaluation is essentially a field of the social sciences, this handbook chapter aims to guide researchers and policymakers working 
in the social sciences to enhance the quality of research evaluations by presenting an overview of current topics.

The reality of research evaluations in social sciences is that not everything important in social sciences can be counted, and everything that can be counted may not be important. Thanks to research policies prepared with the awareness of this fact, it will be possible to conduct accurate research performance evaluations. Recent publications on research evaluations show that the disciplinary differences of social sciences have been among the research topics, the issues that negatively affected the research evaluations have been taken into consideration, and the new techniques suitable for the structure of social sciences have been developed. Current studies in research evaluations can be classified into four main research topics: Altmetrics, content-based citation analysis, peer-review and scientific visualization.

There are various debates on altmetrics today, where social media is gaining more and more importance. It is clear that altmetrics cannot replace traditional research evaluation systems. However, altmetrics will be one of the essential methods for measuring the societal impact of research in the field of social sciences where social impact is extremely important. On the other hand, if the altmetric analyses go beyond numbers and consider the contents using machine learning techniques, they can produce much more meaningful results.

For almost 50 years, bibliometricians have pointed out the necessity of leaving citation counting behind and focusing on the contents of the citations. With the improvements in natural language processing methods and computational linguistics, it has become possible to implement it. Various systems are able to classify citation sentences according to their meanings or places in the text. These systems are an important improvement to traditional citation counting.

Another approach that will improve research evaluations is open and transparent peerreview. The current developments for peer-review processes are crowdsourcing in peer-review, immediate publication and post-publication peer-review.

Social network analysis offers valuable techniques and approaches for research evaluations. These methods are particularly important in terms of providing information for identifying convergent areas, framing disciplines, and determining research potential and collaboration opportunities. Social network analysis will be one of the most important methods for research evaluations in the future.

The main limitation of this study is the use of Web of Science data, which contains journal articles mainly, to present this thematic overview of current topics in research evaluation. However, considering that trending subjects in the literature are generally presented as articles or proceedings at first and the aim of the study is to find emerging subjects, I consider this an acceptable limitation.

One of the most important findings of the study is that open science and transparency are the key points of all the subjects. A wider uptake of open science is key for the improvement of research evaluation processes. Moreover, this applies not only to social sciences but to all fields of science. Open science and research transparency must be accepted as the norm around the world. 


\section{Implications for Research Assessment}

In this study, I discussed the main differences between research evaluation studies conducted in social sciences and the whole research evaluation literature and the diversity of subjects discussed in relation to research evaluation in the social sciences. I examined the subjects of research evaluation in the social sciences, which has a remarkable variety of topics, and the advantages and disadvantages of four current research topics namely altmetrics, content-based citation analysis, peer-review and scientific visualization were provided. The thematic development of each approach, pioneering studies in the literature, historical background and core resources are presented, and it is aimed to provide a guide for those who will begin to work on these subjects. Besides, the results presented in this study are useful for decision-makers and managers. Clearly, research evaluation in the social sciences is an approach rather than a measurement task. Many studies have emphasized that in the social sciences and beyond, the impact is more important than the number of publications or citations. Therefore, it is important to know the developments in the field of research evaluation, to be aware of new methods and techniques and to notice the advantages and disadvantages of these methods before the implementation of critical decisions.

\section{References}

Ausserhofer, D. (2017). Crowd-based peer review can be good and fast. Nature, 546(7656), Article 9. https://doi.org/10.1038/546009a

Bornmann, L. (2011). Scientific peer review. Annual Review of Information Science and Technology, 45(1), 197-245. https://doi.org/10.1002/aris.2011.1440450112

Bornmann, L., \& Daniel, H. (2008). What do citation counts measure? A review of studies on citing behavior. Journal of Documentation, 64(1), 45-80. https://doi.org/10.1108/00220410810844150

Buschman, M., \& Michalek, A. (2013). Are alternative metrics still alternative? Bulletin of the Association for Information Science and Technology, 39(4), 35-39. https://doi.org/10.1002/bult.2013.1720390411

Cameron, W. B. (1963). Informal sociology: A casual introduction to sociological thinking. Random House.

Cheung, M. K. (2013). Altmetrics: Too soon for use in assessment. Nature, 494(7436), 176. https://doi.org/10.1038/494176d

Chubin, D. E., \& Moitra, S. D. (1975). Content analysis of references: Adjunct or alternative to citation counting? Social Studies of Science, 5(4), 423-441. https://doi.org/10.1177/030631277500500403

Clarivate. (2018). Back to the future: Institute for scientific information re-established within clarivate analytics. https://clarivate.com/news/back-future-institute-scientificinformation-re-established-within-clarivate-analytics/ 
Clements, F. O. (1926). Evaluating research ideas. The Scientific Monthly, 22(5), 441-444. https://www.jstor.org/stable/7655

Ding, Y., Zhang, G., Chambers, T., Song, M., Wang, X., \& Zhai, C. (2014). Content-based citation analysis: The next generation of citation analysis. Journal of the Association for Information Science and Technology, 65(9), 1820-1833. https://doi.org/10.1002/asi.23256

Garfield, E. (1973). Citation frequency as a measure of research activity and performance. In Essays of an information scientist (Vol. 1, pp. 406-408). ISI Press. http://garfield.library.upenn.edu/volume1.html

Garfield, E. (1963). Citation indexes - Closing the information gap between the pure and applied sciences [Conference presentation]. Annual Meeting of the Education American Society for Engineering Education, Philadelphia, PA, United States. http://garfield.library.upenn.edu/papers/ciclosinginfogap1963.pdf

Garfield, E. (1964). Citation indexing: A natural science literature retrieval system for the social sciences. American Behavioral Scientist, 7(10), 58-61. https://doi.org/10.1177\%2F000276426400701017

Garfield, E. (1970). Can citation indexing be automated? In Essays of an Information Scientist (Vol. 1, pp. 84-90). ISI Press. http://garfield.library.upenn.edu/volume1.html (Original work published 1965)

Giménez-Toledo, E. (2018). Research assessment in humanities and social sciences in review. Revista Española de Documentación Científica, 41(3), Article e208. https://doi.org/10.3989/redc.2018.3.1552

Hassan, S.-U., Saleem, A., Soroya, S. H., Safder, I., Iqbal, S., Jamil, S., Bukhari, F., Aljohani, N. R., \& Nawaz, R. (2020). Sentiment analysis of tweets through altmetrics: A machine learning approach. Journal of Information Science. Advance online publication. https://doi.org/10.1177/0165551520930917

Hicks, D., Wouters, P., Waltman, L., De Rijcke, S., \& Rafols, I. (2015). Bibliometrics: The Leiden manifesto for research metrics. Nature, 520(7548), 429-431. https://doi.org/10.1038/520429a

Horbach, S. P. J. M., \& Halffman, W. (2018). The changing forms and expectations of peer review. Research Integrity and Peer Review, 3(1), Article 8. https://doi.org/10.1186/s41073-018-0051-5

Huang, M.-H., \& Chang, Y.-W. (2008). Characteristics of research output in social sciences and humanities: From a research evaluation perspective. Journal of the American Society for Information Science and Technology, 59(11), 1819-1828. https://doi.org/10.1002/asi.20885 
Iqbal, S., Hassan, S.-U., Aljohani, N. R., Alelyani, S., Nawaz, R., \& Bornmann, L. (2020). A decade of in-text citation analysis based on natural language processing and machine learning techniques: An overview of empirical studies. ArXiv. http://arxiv.org/abs/2008.13020

Kovanis, M., Trinquart, L., Ravaud, P., \& Porcher, R. (2017). Evaluating alternative systems of peer review: A large-scale agent-based modelling approach to scientific publication. Scientometrics, 113(1), 651-671. https://doi.org/10.1007/s11192-017-2375-1

Kulczycki, E., \& Korytkowski, P. (2020). Researchers publishing monographs are more productive and more local-oriented. Scientometrics, 125(2), 1371-1387. https://doi.org/10.1007/s11192-020-03376-x

Kulczycki, E., Guns, R., Pölönen, J., Engels, T. C. E., Rozkosz, E. A., Zuccala, A. A., Bruun, K., Eskola, O., Starčič, A. I., Petr, M., \& Sivertsen, G. (2020). Multilingual publishing in the social sciences and humanities: A seven-country European study. Journal of the Association for Information Science and Technology, 71(11), 1371-1385. https://doi.org/10.1002/asi.24336

Lee, C. J., Sugimoto, C. R., Zhang, G., \& Cronin, B. (2013). Bias in peer review. Journal of the American Society for Information Science and Technology, 64(1), 2-17. https://doi.org/10.1002/asi.22784

Line, M. B. (1971). The information uses and needs of social scientists: An overview of INFROSS. Aslib Proceedings, 23(8), 412-434. https://doi.org/10.1108/eb050298

Liu, X., Wei, Y., \& Zhao, Z. (2020). How researchers view altmetrics: An investigation of ISSI participants. Aslib Journal of Information Management, 72(3), 361-378. https://doi.org/10.1108/AJIM-07-2019-0165

Marjanovic, S., Hanney, S., \& Wooding, S. (2009). A historical reflection on research evaluation studies, their recurrent themes and challenges: Technical report (ED507615). ERIC. https://eric.ed.gov/?id=ED507615

Merriam-Webster. (n.d.). Social media. In Merriam-Webster.com dictionary. Retrieved July 12, 2021, from https://www.merriam-webster.com/dictionary/social+media

Merton, R. K. (1968). The Matthew effect in science: The reward and communication systems of science are considered. Science, 159(3810), 56-63. https://doi.org/10.1126/science.159.3810.56

Moravcsik, M. J., \& Murugesan, P. (1975). Some results on the function and quality of citations. Social Studies of Science, 5(1), 86-92. https://doi.org/10.1177\%2F030631277500500106

National Information Standards Organization. (2016). Outputs of the NISO alternative assessment metrics project. https://groups.niso.org/apps/group_public/download.php/17091/ 
Priem, J., Taraborelli, D., Groth, P., \& Neylon, C. (2010). Altmetrics: A manifesto. Altmetrics. http://altmetrics.org/manifesto/

Scott, J. (1988). Social network analysis. Sociology, 22(1), 109-127. https://doi.org/10.1177/0038038588022001007

Shema, H., Bar-Ilan, J., \& Thelwall, M. (2014). Do blog citations correlate with a higher number of future citations? Research blogs as a potential source for alternative metrics. Journal of the Association for Information Science and Technology, 65(5), 1018-1027. https://doi.org/10.1002/asi.23037

Swatman, R. (2015, August 19). 1971: First ever e-mail. Guinness World Records. https://www.guinnessworldrecords.com/news/60at60/2015/8/1971-first-ever-email-392973

Tahamtan, I., Afshar, A. S., \& Ahamdzadeh, K. (2016). Factors affecting number of citations: A comprehensive review of the literature. Scientometrics, 107(3), 1195-1225. https://doi.org/10.1007/s11192-016-1889-2

Taşkın, Z., \& Al, U. (2018). A content-based citation analysis study based on text categorization. Scientometrics, 114(1), 335-357. https://doi.org/10.1007/s11192-017-2560-2

Thelwall, M. (2020). Measuring societal impacts of research with altmetrics? Common problems and mistakes [Special issue]. Journal of Economic Surveys. Advance online publication. https://doi.org/10.1111/joes.12381

Tomkins, A., Zhang, M., \& Heavlin, W. D. (2017). Reviewer bias in single- versus double-blind peer review. Proceedings of the National Academy of Sciences, 114(48), 12708-12713. https://doi.org/10.1073/pnas.1707323114

Triggle, C. R., \& Triggle, D. J. (2007). What is the future of peer review? Why is there fraud in science? Is plagiarism out of control? Why do scientists do bad things? Is it all a case of: "All that is necessary for the triumph of evil is that good men do nothing?" Vascular Health and Risk Management, 3(1), 39-53. https://www.proquest.com/scholarly-journals/what-is-futurepeer-review-why-there-fraud/docview/2222956069/se-2?accountid=203424

Waltman, L. (2016). A review of the literature on citation impact indicators. Journal of Informetrics, 10(2), 365-391. https://doi.org/10.1016/j.joi.2016.02.007

Wasserman, S., \& Faust, K. (1994). Social network analysis: Methods and applications. Cambridge University Press.

Williams, A. E. (2017). Altmetrics: An overview and evaluation. Online Information Review, 41(3), 311-317. https://doi.org/10.1108/OIR-10-2016-0294

Wilsdon, J., Allen, L., Belfiore, E., Campbell, P., Curry, S., Hill, S., Jones, R., Kain, R., Kerridge, S., Thelwall, M., Tinkler, J., Viney, I., Wouters, P., Hill, J., \& Johnson, B. (2015). The metric tide: Report of the independent review of the role of metrics in research assessment and management. HEFCE. https://doi.org/10.13140/RG.2.1.4929.1363 


\section{Appendix 1}

Co-occurrence network of research evaluation studies (a) and research evaluation studies in social sciences (b)

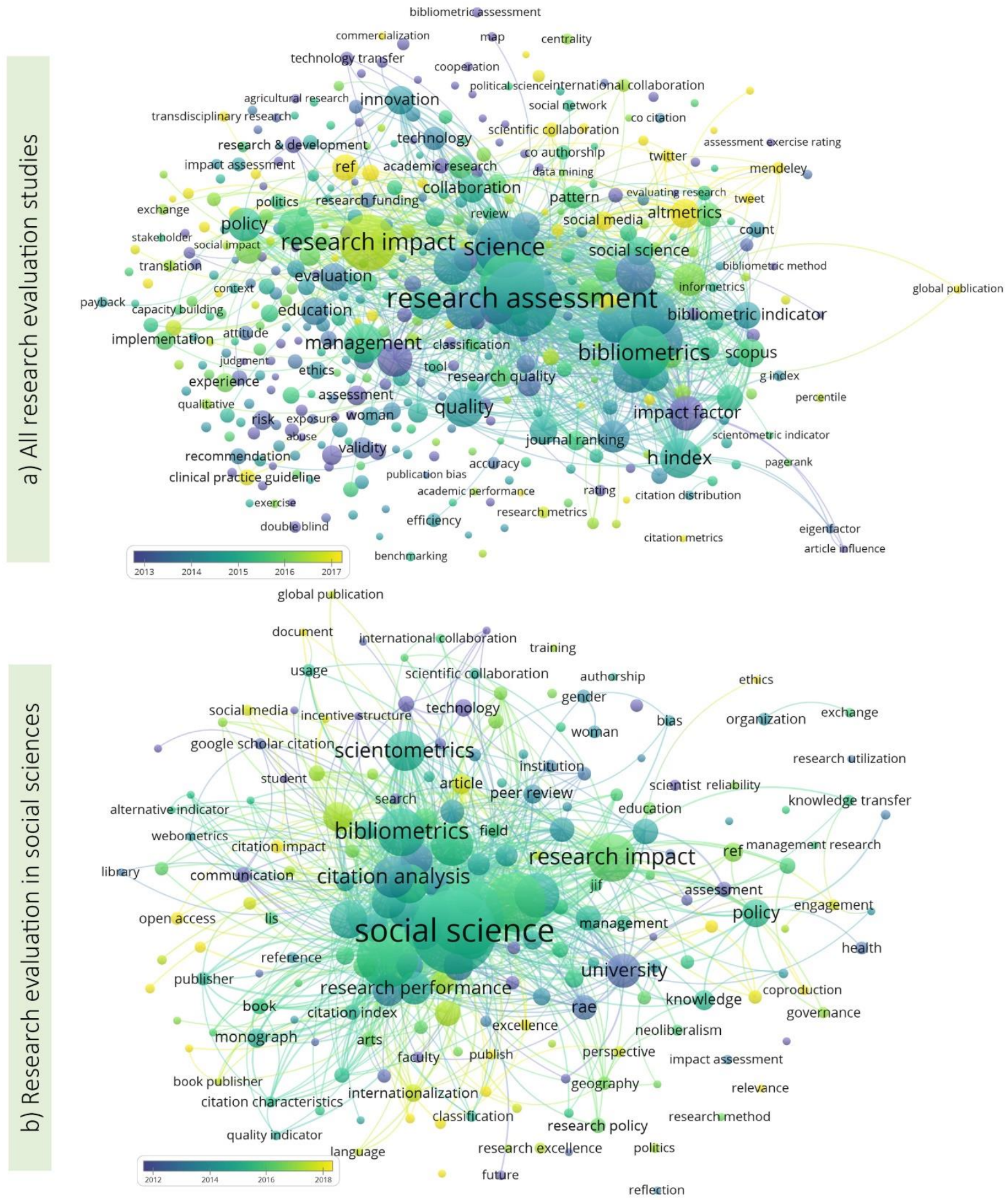

